\title{
SPACE EXPERIMENTS WITH PARTICLE ACCELERATORS: SEPAC
}

\author{
J. L. Burch, ${ }^{1}$ W. T. Roberts, ${ }^{2}$ W. W. L. Taylor, ${ }^{3}$ \\ N. Kawashima, ${ }^{4}$ J. A. Marshall, ${ }^{\text {S. L. Moses, }}{ }^{3}$ T. Neubert, ${ }^{5}$ \\ S. B. Mende ${ }^{6}$ and E. Y. Choueiri ${ }^{7}$ \\ 1 Southwest Research Institute, San Antonio, TX 78228-0510, U.S.A. \\ 2 NASAMarshall Space Flight Center, Huntsville, AL 35812, U.S.A \\ ${ }^{3}$ Nichols Research Corporation, Arlington, VA 22209, U.S.A. \\ 4 ISAS, Tokyo, Japan \\ 5 The University of Michigan, Ann Arbor, MI 48109-2143, U.S.A. \\ 6 Lockheed Palo Alto Research Laboratory, Palo Alto, CA 94304, U.S.A. \\ 7 Princeton University, Princeton, NJ 08544, U.S.A.
}

\section{ABSTRACT}

The Space Experiments with Particle Accelerators (SEPAC), which flew on the ATLAS 1 mission, used new techniques to study natural phenomena in the Earth's upper atmosphere, ionosphere and magnetosphere by introducing energetic perturbations into the system from a high power electron beam with known characteristics. Properties of auroras were studied by directing the electron beam into the upper atmosphere while making measurements of optical emissions. Studies were also performed of the critical ionization velocity phenomenon.

\section{INTRODUCTION}

The Space Experiments with Particle Accelerators (SEPAC) were conducted as part of the ATLAS 1 Spacelab mission from March 24 through April 2, 1992. One of the objectives was to perform artificial aurora experiments from orbit using high-power electron beams and the optical imaging capability of the Atmospheric Emissions Photometric Imaging (AEPI) instrument $/ 1$. The SEPAC electron beam accelerator (EBA) is capable of injecting electrons with beam energies up to 6.25 $\mathrm{keV}$. At this energy the perveance-limited electron gun can emit beam currents of up to $1.21 \mathrm{~A}$. The previous flight of SEPAC on Spacelab $1 / 2 /$ showed that at these levels special means of neutralizing the Shuttle are necessary; therefore, for ATLAS 1 the SEPAC instrument complement included three $122-\mathrm{cm}$ diameter conductive spheres for charge collection and a $1.6 \mathrm{~A}$ hollow-cathode $\mathrm{Xe}^{+}$plasma contactor. The flight data show that the effectiveness of these charge neutralization devices was sufficient for injection of electron beams up to the highest beam currents available with the SEPAC EBA. Another objective of SEPAC was to conduct neutral xenon releases from the plasma contactor (PC) to test the predictions of the critical ionization velocity theory.

\section{EXPERIMENT DESCRIPTION}

SEPAC is a joint U.S.-Japan investigation of the interaction of electron beams, plasma and neutral gas with the Earth's upper atmosphere, ionosphere and magnetosphere. It makes use of the large mass, volume and power capabilities of Shuttle/Spacelab as well as the interactive control that is possible through the involvement of payload and mission specialists. The first flight of SEPAC was with the Spacelab 1 mission (STS-9) in late November and early December 1983. Recently an upgraded instrument complement was included as part of the ATLAS 1 payload on STS-45 in late March and early April 1992. The upgraded SEPAC instrumentation is described by Burch et al. 13 . Table 1 shows the SEPAC instrument complement as flown on the ATLAS 1 payload. 
TABLE 1 SEPAC Instrumentation for ATLAS 1

\begin{tabular}{|c|c|c|}
\hline Instrument & Parameter & Range \\
\hline \multirow[t]{6}{*}{ Electron Beam Accelerator (EBA) } & Energy & 0 to $6.25 \mathrm{keV}$ \\
\hline & Current & 0 to $1.21 \mathrm{~A}$ \\
\hline & Perveance & $2.5 \times 10^{-6} \mathrm{AV}^{-1.5}$ \\
\hline & Initial Beam Diameter & $20 \mathrm{~mm}$ \\
\hline & Deflection & 0 to $30^{\circ}$ from axis \\
\hline & Modulation & $\leq 5 \mathrm{kHz}$ \\
\hline \multirow[t]{4}{*}{ Xenon Plasma Contactor (PC) } & Ion-electron production rate & $1.6 \mathrm{~A}$ \\
\hline & Operation time available & 1500 hrs. \\
\hline & Neutral gas pulse width & $100 \mathrm{~ms}$ (programmable) \\
\hline & Number of ejected atoms & $-6 \times 10^{22}$ per pulse \\
\hline Low-frequency plasma wave probe & Frequency & $0.75 \times 10 \mathrm{kHz}$ \\
\hline High-frequency plasma wave probe & Frequency & 0.1 to $10.5 \mathrm{MHz}$ \\
\hline Wideband plasma wave probe & Frequency & $\begin{array}{c}0.4 \text { to } 10 \mathrm{kHz} \\
0.1 \text { to } 4.2 \mathrm{MHz} \\
\text { (or } 4.0 \text { to } 7.5 \mathrm{MHz} \text { ) }\end{array}$ \\
\hline \multirow[t]{4}{*}{ Floating probes } & Distances from pallet & $290 \mathrm{~mm}, 540 \mathrm{~mm}, 790 \mathrm{~mm}$ \\
\hline & Frequency & 0 to $400 \mathrm{~Hz}$ \\
\hline & Potential & $-8 \mathrm{kV}$ to $+8 \mathrm{kV}$ \\
\hline & Resolution & $6 \mathrm{~V}$ \\
\hline \multirow[t]{5}{*}{ Energetic electron analyzer } & Energy & 0.1 to $15 \mathrm{keV}$ \\
\hline & Energy resolution & $\Delta \mathrm{E} / \mathrm{E}=0.18$ \\
\hline & Angular acceptance & $4^{\circ}$ by $10^{\circ}$ \\
\hline & Sample rate & $100 \mathrm{~Hz}$ \\
\hline & Energy sweep time & $320 \mathrm{~ms}$ \\
\hline \multirow[t]{3}{*}{ Langmuir probe } & Density & $10^{4}$ to $10^{8} \mathrm{e} \mathrm{cm}^{-3}$ \\
\hline & Temperature & 600 to $5000^{\circ} \mathrm{K}$ \\
\hline & Sample rate & $\begin{array}{c}1 \mathrm{kHz} \text { (current) } \\
250 \mathrm{~Hz} \text { (voltage) }\end{array}$ \\
\hline \multirow[t]{2}{*}{ Ionization gauge } & Pressure gauge & $5 \times 10^{-8}$ to $5 \times 10^{-4}$ Torr \\
\hline & Sample rate & $1 \mathrm{kHz}$ \\
\hline
\end{tabular}




\section{ARTIFICIAL AURORA EXPERIMENT}

Artificial auroral experiments had been conducted previously from sounding rockets $/ 4,5,6,7,8 /$. The results of the previous experiments led to the expectation that the SEPAC EBA, at highest power, would produce an artificial aurora characterized by an emission with a diameter of about 100-150 $\mathrm{m}$ at altitudes of 100-120 km. However, because of the favorable viewing geometry from orbit, the artificial aurora emissions were imaged over the full extent of the curved magnetic field lines from near the Shuttle altitude of $295 \mathrm{~km}$ down to the $110-120 \mathrm{~km}$ altitude regime. Also present in the images were afterglows, which appeared as emission "tails" extending up to $\sim 1 \mathrm{~km}$ in the wake direction. Contrasts between SEPAC and the previous experiments include the facts that (1) the optical imaging measurements were made from the same spacecraft from which the electron beam was injected rather than from the ground or aircraft, (2) total charge neutralization was accomplished with the charge-collection spheres and the plasma contactor; and (3) the artificial auroras were produced in the auroral zone and in the neighborhood of natural auroras.

In each of the three artificial aurora experiments that were performed on ATLAS 1, twenty electron beams were injected downward from an altitude of $295 \mathrm{~km}$ with $0^{\circ}$ pitch angle at relatively high southern magnetic latitudes $\left(65-67^{\circ}\right)$. During the first and third experiments, optical observations were made with the AEPI instrumentation. In the first experiment white-light images were acquired at a rate of $30 \mathrm{~Hz}$, while in the third experiment these high-rate white-light images were supplemented by images at $4278 \AA$, which were integrated over 1 second. The electron beam pulses were injected once every 15 seconds at the maximum energy and current $(6.25 \mathrm{keV}, 1.21 \mathrm{~A})$ with pulse widths of 1 second.

Figure 1 shows two $4278 \dot{A}$ images that were obtained about 4 minutes apart in the southern auroral zone during the third artificial aurora experiment. In Figure la the artificial aurora is located in the dark region near a quiet auroral arc, while in Figure $\mathrm{lb}$ the artificial aurora is superimposed upon a large naturally occurring auroral arc. Each artificial aurora image contains significant spatial structure, the most persistent features being a tapered extension toward the bottom of the image and (particularly noticeable in Figure 1a) a trail in the Shuttle wake direction, possibly indicating an afterglow phenomenon. The travel time of the beam to the $110-\mathrm{km}$ level is only about $5 \mathrm{~ms}$, and the $4278 \AA$ emission is prompt, with a lifetime of $<1 \mu \mathrm{s}$; therefore, the wake trail was not predicted. The afterglow present in the wake trail may have been produced by induced electron precipitation, caused perhaps by an enhancement of ionospheric Pederson conductivity produced by the artificial beams, although this possibility needs to be investigated further. Another possibility is a beam-plasma interaction that persists for some time after the beam is turned off [Wilhelm et al., 1985]

The tapered extensions toward the bottom of the images in Figures $1 \mathrm{a}$ and $\mathrm{lb}$ are produced by the curvature of the magnetic field line. For this experiment the Shuttle was moving generally eastward, or to the left in Figure 1, so south and north are toward the top and bottom of the figures, respectively. The AEPI has a field of view of $20^{\circ}$, so at $110 \mathrm{~km}$ the width of the images in Figure 1 is about $80 \mathrm{~km}$. The displacement of a dipole field line at a magnetic latitude of $65^{\circ}$ between $295 \mathrm{~km}$ and $110 \mathrm{~km}$ because of field-line curvature is about $1.8 \mathrm{~km}$, which is consistent with the images in Figure 1. The bottom tip of the downward tapered extensions in Figure 1 is, then, the lower extension of the artificial aurora at altitudes of about $110 \mathrm{~km}$. Detailed analysis of the images is reported by Mende et al. $/ 1 /$.

Future experiments are needed to take advantage of the much greater detectability of the artificial aurora emissions from orbit in performing more extensive spectral analyses and in using the artificial electron beams to sense remotely electric fields in the auroral zone. The fact that the artificial auroras are easily detectable even when superimposed on bright natural auroras supports the possibility that upward-propagating electron beams, reflected by parallel electric fields above the aurora, would produce detectable artificial auroras, which could be used to map the strength and spatial distributions of the parallel E-fields. 


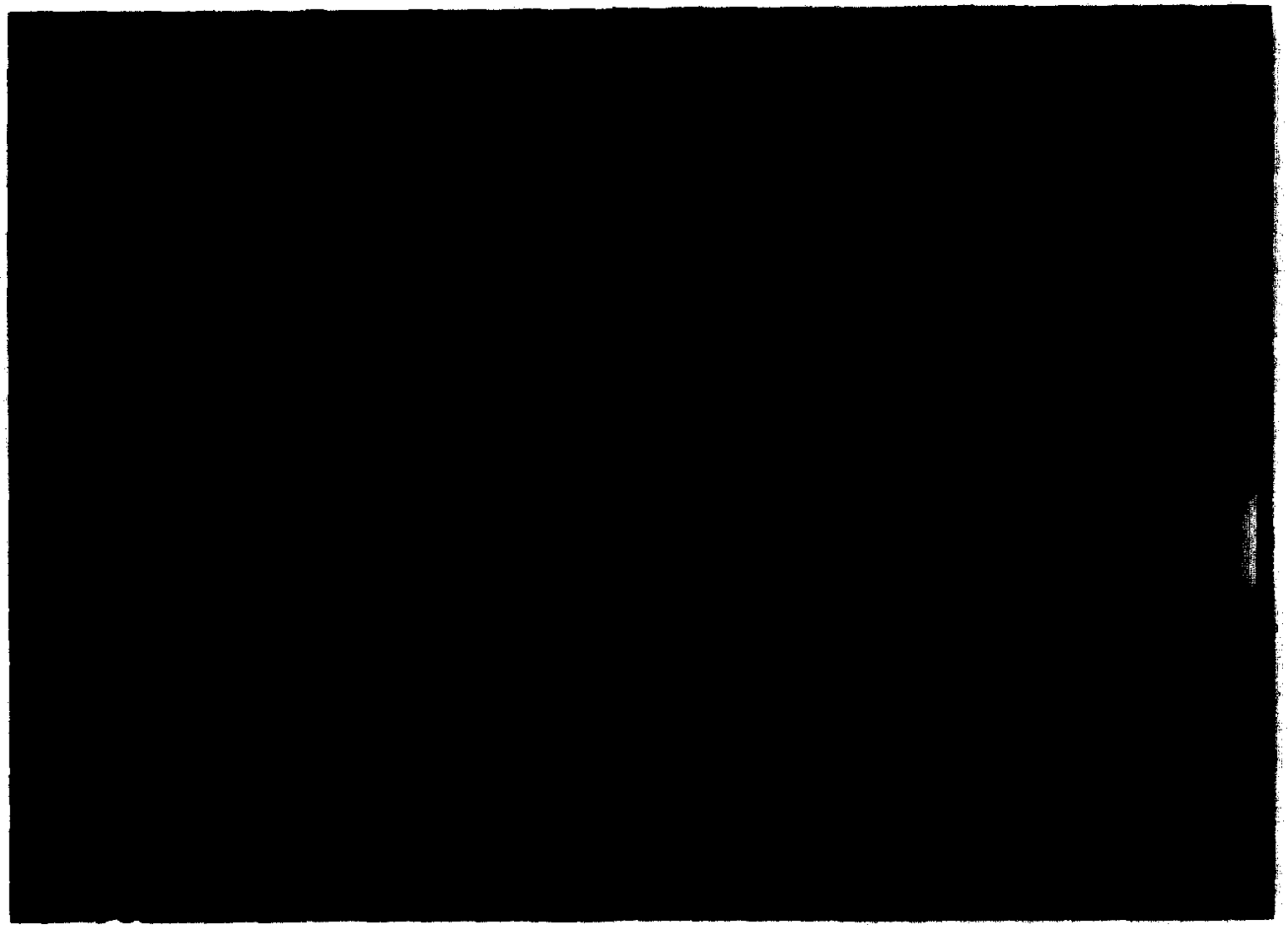

Figure 1a

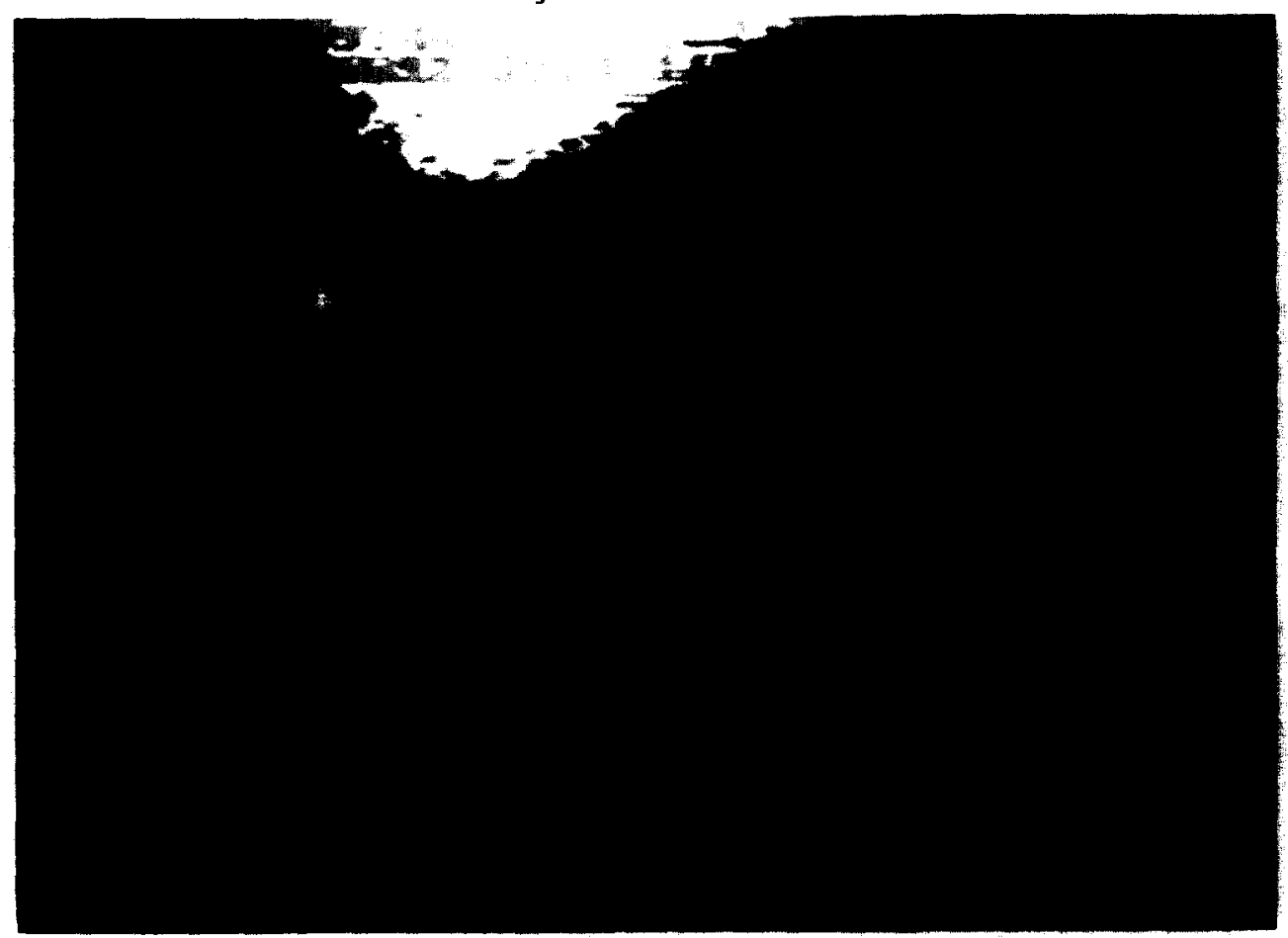

Pigure 1b

Fig. 1. (a) Artificial aurora image in $4278 \AA$. To the left is a quiet auroral arc; in the upper right is the artificial aurora. The image was obtained by the AEPI instrument $/ 11 /$, which viewed downward along the magnetic field direction, during a une-second period beginning at 16:01:59 UT on March 26,1992. The direction of motion of the Shuttle Orbiter was to the left, so the natural auroral arc is broadened in the horizontal direction by about $10 \%$. The width of the image at the $110-\mathrm{km}$ level is about $80 \mathrm{~km}$. The color bar is linear from top to bottom and extends from 0 to about $5 \mathrm{kR}$. (b) Same as (a) except that in this case the image was obtained over the one-second period beginning at 15:57:44 UT on March 26, 1992, and the artificial aurora was superimposed upon a large auroral are. 


\section{CRITICAL IONIZATION VELOCITY (CIV) EXPERIMENT}

The Critical Ionization Velocity (CIV) theory, first postulated by Alfven $19 /$, states that neutral gas travelling perpendicular to a magnetic field will suddenly become ionized when its velocity in the rest frame of the magnetic field reaches a threshold value such that the kinetic energy of the gas in that frame is equal to its ionization potential $\left(v_{\text {erit }}=\sqrt{2 \mathrm{e} \phi_{\text {ion }} / \mathrm{m}}\right)$.

The CIV phenomenon has been suspected to play an important role in various plasma dynamics situations ranging from cometary comas and astrophysical problems to spacecraft environment interactions and ionization in magneto-plasma-dynamic (MPD) thrusters. While CIV has been observed in many laboratory experiments, a definitive and unambiguous observation of this phenomenon in space has proved to be elusive. Torbert /10/ gives a review of many of the attempts to observe CIV in the ionosphere. This section reports on a CIV experiment that was performed on the ATLAS 1 mission as part of the Space Experiments with Particle Accelerators (SEPAC) using the plasma contactor (Table 1) in the neutral gas mode.

The SEPAC CIV experiment consisted of a series of $100 \mathrm{~ms}$ neutral xenon releases, repeated once every five seconds for five minutes. The release velocity of the xenon from the PC at the 245 psi nominal plenum tank pressure is on the order of $30.5 \mathrm{~m} / \mathrm{s}$; therefore, the neutral xenon had essentially the orbital velocity of $\geq 7 \mathrm{~km} / \mathrm{s}$ when released from the PC regardless of the orientation of the release with respect to the velocity vector. In order to satisfy the CIV criterion, the velocity perpendicular to the magnetic field must exceed the critical value; therefore, the planned experiments were performed at high latitudes, where the angle between the orbital velocity and the field line is nearly $90^{\circ}$.

The CIV experiment was performed twice during ATLAS-1: once in the planned configuration (payload bay in the wake) and once with the payload bay toward the Earth. The latter configuration is not optimum for the CIV experiment because the gas is released perpendicular to the velocity vector, i.e., not into the ram or wake; however, we chose to take advantage of available experiment time with the Orbiter in this attitude.

\section{RESULTS FROM SEPAC DIAGNOSTICS}

Figure 2 shows SEPAC diagnostic package (Table 1) data from 16:07:35 to 16:08:05 UT on March 27 (Day 87), 1992. The first CIV experiment began at 16:07:40 UT. The payload bay was toward Earth at that time (Fig.1b). The top plot shows the neutral gas fast acting valve status as "on" when the valve is open; the valve stays open for approximately 100 msec every 5 sec. The second plot is the Langmuir probe current (top) and voltage (bottom). Before the beginning of the experiment, the probe voltage was swept in order to obtain the ambient electron temperature and density. Once the neutral gas releases began, the voltage was held constant at $+9 \mathrm{~V}$ (the maximum applied voltage) in order to record density fluctuations. Unfortunately, voltage sweeps immediately before the start of the releases show that the probe does not reach the electron saturation limit at this voltage. During the releases the current does reach the maximum level that can be read by the probe, increasing by a factor of at least 60 as compared to the background level.

\section{COMPARISON WITH CIV MODELS}

In the paper by Marshall et al. /11/, a two-part code was used to model possible CIV effects for the experimental configuration of the first CIV experiment. The first part is a linear and quasilinear wave (and instability) model for wave generation, saturation, and particle heating during a CIV interaction given the ambient and release parameters. This model takes into account many realistic effects such as magnetization, full kinetic effects, collisions, spatial effects, and electromagnetic polarization. The second part of the code is a set of necessary conditions or criteria that a CIV release in space must satisfy in order for a CIV interaction to be possible. Most of these criteria have been discussed by Murad and Lai $/ 12 /$. 


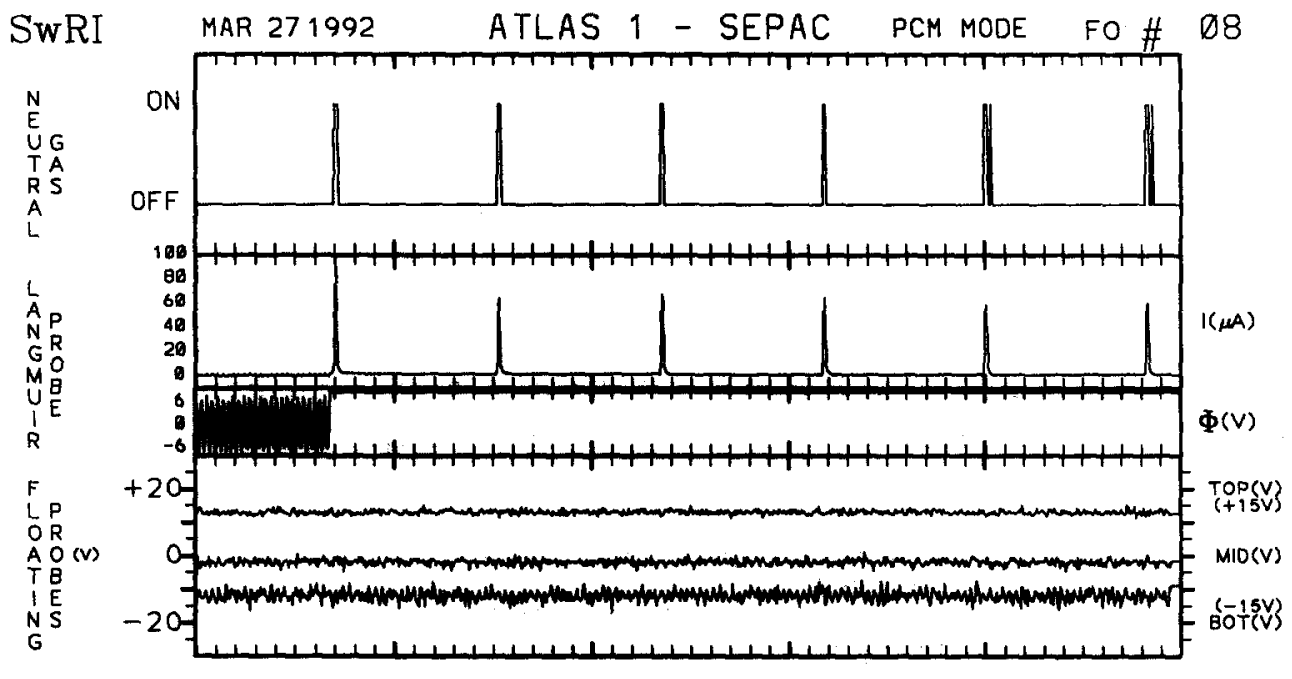

$\begin{array}{lccccc}\text { UT(HM)16.07 } & 16.07 & 16.07 & 16.07 & 16.07 & 16.08 \\ \text { UT (S) 35.43i } & 41.431 & 47.431 & 53.431 & 59.431 & 5.431 \\ \text { LAT } & -57 & -57 & -57 & -57 & -57 \\ \text { LON } & 111 & 112 & 112 & 193 & 114\end{array}$

Fig. 2. Data from the SEPAC diagnostic package plotted against universal time from 16:07:35 to 16:08:05 on Day 87 (March 27), 1992. The first panel shows the neutral gas release valve status (ON/OFF). Each pulse lasts 100 msec and represents on the order of 1/6 mole of neutral xenon. The second 2 panels show the Langmuir probe current (top) and applied voltage (bottom). As soon as the releases begin, the probe voltage is held constant at $+9 \mathrm{~V}$. The bottom plot shows the voltage on the three sensors of the floating probe. Ancillary data are given at the bottom of the plot along the $x$ axis.

\section{CRITERIA}

Marshall et al. /11/ used their model to evaluate several CIV criteria for the SEPAC releases. Their results are summarized in Table 2.

\section{CONCLUSIONS}

The prospect for a CIV type interaction for this particular release is good judging from the application of the above criteria. The criteria are mostly (and at worst marginally) met at distinces of 100 meters or so from the spacecraft. One criterion not considered stipulates that the dimension of the cloud must exceed the wavelength of the unstable mode responsible for electron energization. The evaluation of this criterion must await the sady of the wave physics of this particular release. Finally, criteria for disqualifying the possible role of other ionization mechanisms in these releases (such as charge-exchange and the entrainment of collisionally ionized neutrals to the probe as discussed by Sasaki /20/) have not yet been addressed quantitatively. 
TABLE2 CIV Criteria

\begin{tabular}{|c|c|c|c|c|}
\hline $\begin{array}{l}\text { Parameter/ } \\
\text { Phenomenon }\end{array}$ & Reference & Criterion & Requirement & Result \\
\hline Release Velocity & $\begin{array}{l}\text { Papadopoulos } \\
\text { /13/ }\end{array}$ & $v_{\mathrm{rel}} \geq v_{\mathrm{ci}}$ & $v_{\text {rel }} \geq 4.2 \mathrm{~km} / \mathrm{s}$ & $v_{\text {rel }}=7.4 \mathrm{~km} / \mathrm{s}$ \\
\hline $\begin{array}{l}\text { Magnetic Field } \\
\text { Strength }\end{array}$ & $\begin{array}{l}\text { Axnäs and } \\
\text { Brenning /14/ }\end{array}$ & $\omega_{p} / \omega_{\infty}>\sqrt{m_{c} / m_{b}}$ & $\mathrm{~B}<.04 \mathrm{~T}$ & $B \approx 6 \times 10^{-3} \mathrm{~T}$ \\
\hline Pitch Angle & $\begin{array}{l}\text { Lai and Murad } \\
/ 19 /\end{array}$ & $\begin{array}{l}\mathrm{L} \sigma \mathrm{n}_{\mathrm{r}}>\sin \alpha>v_{\mathrm{ci}} / v_{\mathrm{rt}} \\
(\mathrm{L}=\text { cloud dimension, } \sigma=\text { electron- } \\
\text { impact ionization cross-section) }\end{array}$ & $33<\alpha<90$ & $\alpha \sim 80^{\circ}-90^{\circ}$ \\
\hline Collisionality & $\begin{array}{l}\text { Choueiri et al. } \\
115 /\end{array}$ & $R_{\mathrm{Hi}}>\left(v_{\mathrm{rel}}^{2} / v_{\mathrm{ci}}^{2}-1\right)^{-1}$ & $\mathrm{f}_{\text {ooll }}<18 \mathrm{~Hz}$ & $f_{\text {coll }} \geq 96 \mathrm{~Hz}$ \\
\hline $\begin{array}{l}\text { Metastable } \\
\text { Enhancement }\end{array}$ & Lai et al. $/ 16,17 /$ & $\begin{array}{l}t_{\text {is }}<\text { lifetime for metastable state } \\
\left(6 \mathrm{~s}[3 / 2]_{2}\right)\end{array}$ & $t_{\infty \times n}<150 s$ & $t_{\text {sot }}=3 \mu \mathrm{s}-70 \mathrm{~s}$ \\
\hline Mass Loading & $\begin{array}{l}\text { Haerendel } / 18 / \\
\text { Lai and Murad } \\
/ 19 /\end{array}$ & $n_{b}=0.8 n_{a} m_{A} v_{A} / m_{b} v_{\text {rel }}$ & $\Delta \mathrm{n}_{\mathrm{b}}=10^{6} \mathrm{~cm}^{-3}$ & $\Delta \mathrm{n}=10^{6} \mathrm{~cm}^{-3}$ \\
\hline
\end{tabular}

Note: $v_{\mathrm{rel}}$ is the release velocity perpendicular to the magnetic field (B), $v_{\mathrm{s}}$ is the critical ionization velocity; $\omega_{\mathrm{pe}}$ and $\omega_{\mathrm{es}}$ are the electron plasma and cyclotron frequencies; $L$ is the dimension of the released cloud; $\sigma$ is the electron-impact ionization cross section; $\alpha$ is the pitch angle; $\Omega_{H i}$ is the Hall parameter for ions; $t_{i o s}$ is the ionization time; $v_{A}$ is the Alfven velocity; and $n_{4}, m_{4}, n_{2}$, and $m_{k}$ are the cloud and ambient densities and masses, respectively.

\section{ACKNOWLEDGEMENTS}

Many people have contributed to the SEPAC experiment over the years. Professor Tatsuzo Obayashi, who is recently deceased, was the original principal investigator beginning in 1976. Bill Gibson, Bill Tomlinson, George Ferguson of SwRI and Randy Bounds of Nichols Research contributed extensively to the hardware and software efforts. At ISAS numerous scientists and engineers contributed to SEPAC, including Drs. K. Kuriki, M. Nagatomo, K. Ninomiya, and M. Ejiri. We have benefitted greatly from the involvement of co-investigators Dr. Rick Chappell and Professor Peter Banks; the ATLAS-1 crew; the ATLAS Project personnel, under the guidance of Tony O'Neill of MSFC, and Dr. Bob Beattie of Hughes Research Laboratory.

\section{REFERENCES}

1. Mende et al., Artificial auroras in the upper atmosphere: 2. imaging results, Geophys. Res. Lett., 495-498, 1993.

2. Obayashi, T., et al., Space experiments with particle accelerators, Science, 225, 195-196, 1984.

3. Burch, J. L., et al., Artificial auroras in the upper atmosphere: 1. electron beam injections, Geophys. Res. Letr., 491-494, 1993.

4. Hess, W. N., et al., Artificial auroral experiment: experiment and principal results, J. Geophys. Res., 76, 6067-6081, 1971.

5. Davis, T. N., et al., Artificial aurora experiment: ground-based optical observation, J. Geophys. Res., 76, 6082-6092, 1971.

6. Davis, T. N., et al., Artificial aurora conjugate to a rocket-borne electron accelerator, J. Geophys. Res., 85, 1722-1728, 1980.

7. O'Neil, R. R., E. T. P. Lee, and E. R. Huppi, Auroral O('S) production and loss processes: ground-based measurements of the artificial auroral experiment Precede, J. Geophys. Res., 84, 823-833, 1979.

8. Winckler, J. R., The application of artificial electron beams to magnetospheric research, Rev. Geophys. Space Phys., 18, 659-682, 1980.

9. Alfvén, H. On the Origin of the Solar System, Oxford University Press, Oxford, 1954. 
10. Torbert, R. B., Review of critical velocity experiments in the ionosphere, Adv. Space Res., 10(7), 47-58, 1990.

11. Marshall, J. A., et al., CIV experiments on ATLAS 1, Geophys. Res. Lett., 499-502, 1993.

12. Murad, E. and S. T. Lai, personal communication, 1992.

13. Papadopoulos, K., On the shuttle glow: The plasma alternative, Radio Science, 19, 571, 1984.

14. Axnäs, I., and N. Brenning, Experiments on the magnetic field and neutral density limits on CIV interaction, Adv. Space Res., 10, 27-30, 1990.

15. Choueiri, E. Y., A. J. Kelly, and R. G. Jahn, The manifestation of Alfven's hypothesis of critical ionization velocity in the performance of MPD thrusters, 18th International Electric Propulsion Conference, Alexandria, Virginia, 1985.

16. Lai, S., W. McNeil, and E. Murad, The role of metastable states in critical ionization velocity discharges, J. Geophys. Res., 93, 5871-5878, 1988.

17. Lai, S., E. Murad, and W. McNeil, An overview of atomic and molecular processes in critical velocity ionization, IEEE Transactions of Plasma Science, 17, 124, 1989.

18. Haerendel, G., The role of momentum transfer to the ambient plasma in critical ionization velocity experiments, Technical Report SP-195, European Space Agency, Neuilly, France, 1983.

19. Lai, S. T., and E. Murad, Inequality conditions for critical velocity ionization space experiments, accepted for publication in IEEE Transactions on Plasma Science, 1992.

20. Sasaki, S., et al., An enhancement of plasma density by neutral gas injection observed in SEPAC Spacelab-1 Experiment, J. Geomag. Geoelect., 37, 883-894, 1985. 